\title{
GEOMORPHOLOGIC RISK ASSESSMENT IN TECUCEL DRAINAGE BASIN, USING GIS TECHNIQUES
}

DOI: http://dx.doi.org/10.18509/GBP.2016.13

UDC: 551.4-047.44:[528.8:004.6(498)

\author{
Bsc. Student Marian Albu \\ Conf. PhD.Cristian Constantin Stoleriu ${ }^{1}$ \\ PhD Student Andrei Enea \\ PhD Student Marina Iosub \\ PhD Student Oana Elena Hapciuc \\ Prof. PhD. Gheorghe Romanescu
}

Alexandru Ioan Cuza University of Iași, Faculty of Geography and Geology,

Department of Geography, Iasi, Romania

\begin{abstract}
This paper aims to use a multi-parameter method for estimating the geomorphologic risk, in Tecucel drainage basin, Romania. It is located in the South-Eastern region of the country, and it is an tributary of Barlad river, draining important inhabited areas. The population is predominantly rural and mostly based on agricultural activities, therefore the farmlands are extremely important in their lives, the geomorphologic risk leading to potential reduction of arable land, which ensures the very existence of the inhabitants. The evaluation for this type of risk implies the analysis of several morphometrical parameters, out of which the most important are slope, land use, surface curvature, soil etc. The main morphometrical layers are generated from a terrain model, derived from Lidar data. This method includes the classification of each parameter, according to a riskbased logic. Therefore, high values of each parameter will be associated with landslide prone areas. The following process is the combination of all the layers into a final layer, using a geoformula, which will be implemented in GIS software. Among the results, the most relevant is considered to be a map revealing all the risk prone areas, including the overlapping villages. Based on this map, a statistical analysis will be performed, revealing the estimated built-up areas that are prone to be affected, as well as farmland. This proposed approach, which uses GIS techniques to map the geomorphologic risk, is useful to emphasize the potential danger associated to landslides, gully erosion and their direct effect on the human activities.
\end{abstract}

Keywords: geomorphologic, parameters, risk, model

\section{INTRODUCTION}

Landslide risk assessment represents a complex analysis that is based on a variety of techniques and methodologies, which integrates the triggering factors of this phenomenon, by using GIS techniques. The landslide hazard refers to the natural probability of an area to be subjected to slope movements [1].

Landslides represent one of the most important geomorphological phenomena that affects the land in Moldavian Plateau area. The occurence of these phenomena is based on a series of factors such as geological, geomorphological, hydrogeological, climatic and last but not least, anthropogenic factors. Areas affected by these geomorphological 
phenomena are mainly agricultural. Depending on demographic and economic pressure, human settlements have expanded over areas prone to landslides [2].

The making of maps that can illustrate the geomorphological risk has the purpose of identiying the areas which have poor slope stability and cannot be used as areas for construction [3]. The methodologies used in mapping a landslide risk integrate a number of factors influencing their occurrence: lithology, slope, soil texture and land use.

\section{STUDY AREA}

The Tecucel river drainage basin is located in the South-Eastern part of Romania, at the contact between the Moldavian Plateau and the Romanian Plain, originating in the southern tip of Tutova Hills. Here, it overlaps 3 relief sub-units: Vîrlănești Hill, in the Northern side, Tecuciului Plain in the Western, Central and Southern side, and in the South-Eastern side, the Bârlad river meadow (Fig. 1). Tecucel drainage basin is a part of the Bârlad river basin, being a right-side tributary, with an area of $112 \mathrm{~km}^{2}$ and a length of $24 \mathrm{~km}$. The maximum altitude is $307,8 \mathrm{~m}$ in the northern part in Ploscuțeni Hill and the minimum is $37 \mathrm{~m}$ at the confluence with the river tributary in the Southern part of Tecuci City. It has a multianual average flow of $0,38 \mathrm{~m}^{3} / \mathrm{s}$.

In terms of geology, the Tecucel river basin is formed on sedimentary formations of Sarmatian and Pliocene age [4]. The lithology in the study region is caracterized by a large share of areas covered with gravel and sand. In the central part of the basin, lithological classes are distributed that are comprised of clay, which makes the land more exposed to slope displacements.

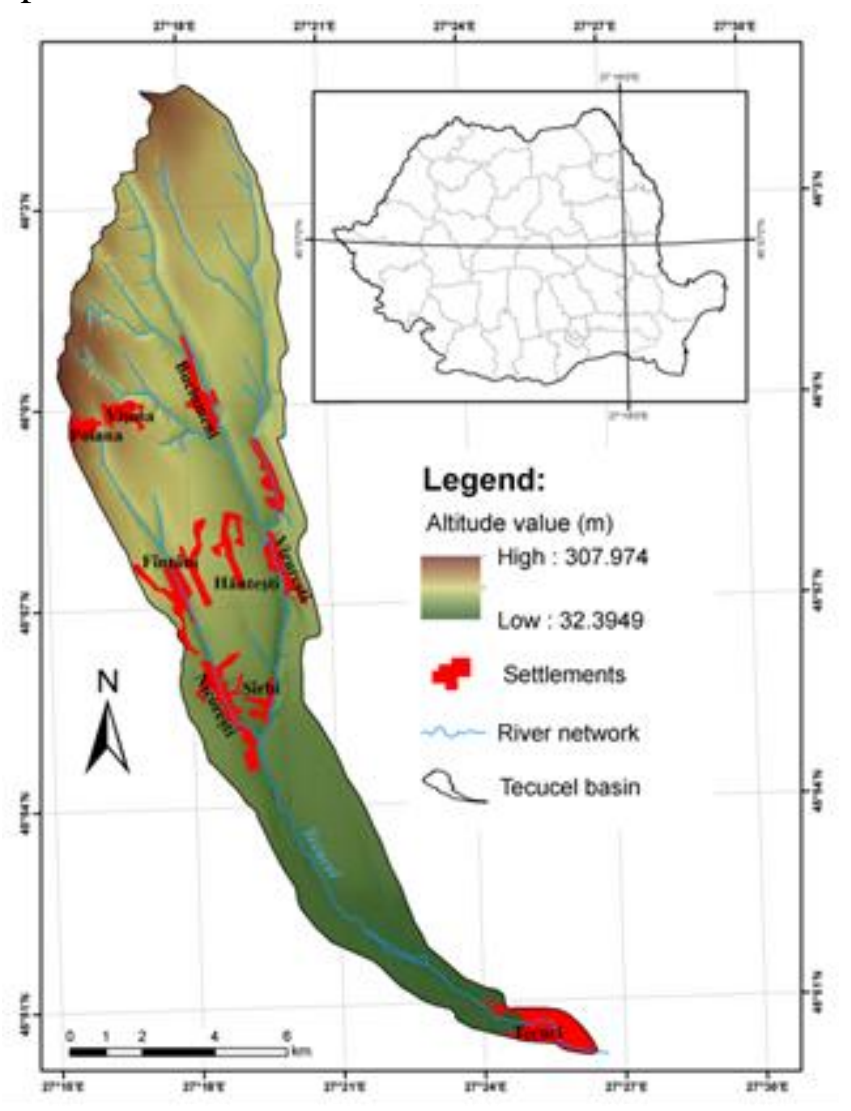

Figure 1. Geographical location of Tecucel basin 
The surface covered in forests is found mostly in the Northern part of the basin, on an area of over $65 \mathrm{~km}^{2}$. The forest serves as a means of protection and stabilization of the areas affected by landslides and gullying, the region being prone to this type of geomorphological processes. The land concentrated to the middle of the basin is used in agriculture, the tillages is arranged as stripes, from the top to the bottom of the hill, meaning that the land is plowed likewise. This type of plowing causes the appearance of geomorphological land forms, such as gullies and ravines, heavily affecting the slopes [5].

The geomorphological risk in the major relief unit, from which the study area is part of, has been analyzed before, the erosion being evaluated in depth [6,7].

In terms of administrative borders, Tecucel river drainage basin is located at the contact between Vrancea and Galați counties, being separated by Siret Valley and it extends over the surface of 6 settlements (5 villages and one city): Ploscuțeni, Brăhășești, Buciumeni, Poiana, Nicorești and Tecuci City.

\section{MATERIALS AND METHODS}

Geomorphological risk assessment was possible by using physical-geographical parameters which pose an important role in causing the landslides in Tecucel drainage basin. The factors taken into account are: geology (the lithology of the study area), soil cover (by texture), slope and land use. The generated GIS layers were classified using values between 0 and 100, depending on the contribution they have in causing a landslide. The final raster was obtained by summing all layers(fig. 2).

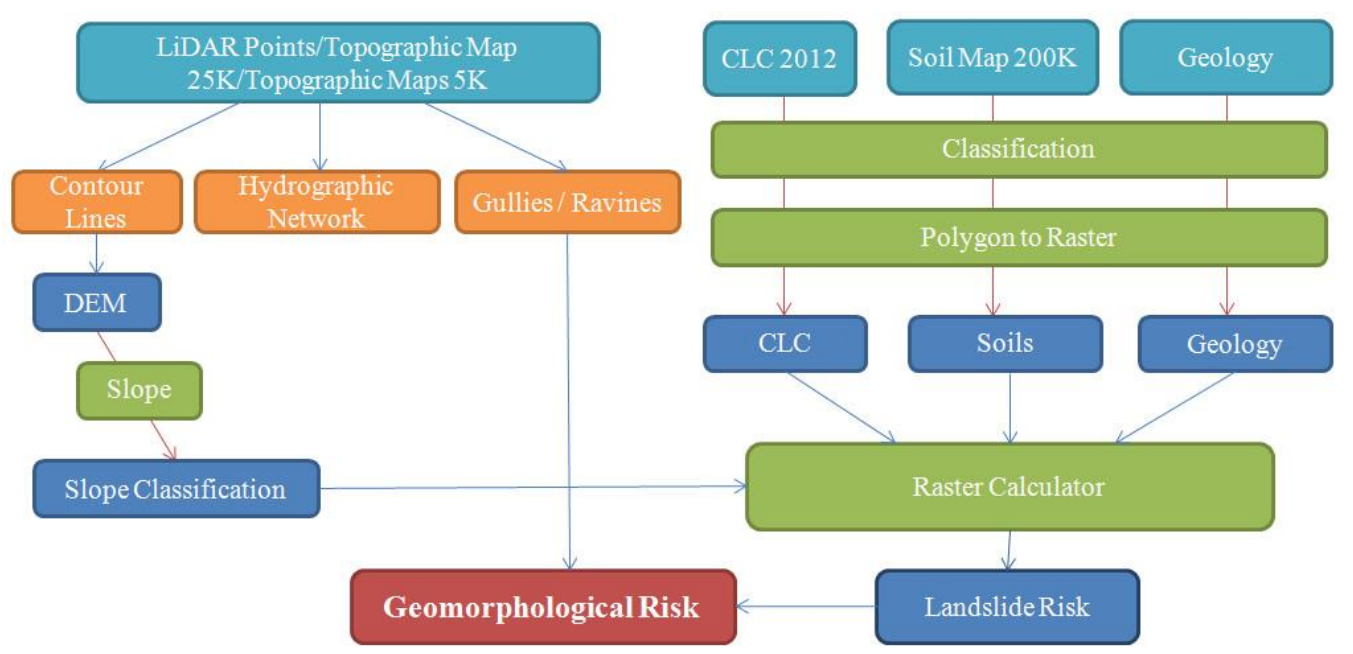

Figure 2. Methodology for identifying areas prone to geomorphologic risk

The risk phenomenon can be analyzed, only by considering the presence of man in the ecuation. We cannot speak of risk in the areas where the anthropic element is entirely absent. This is an important consideration, which was taken into account, in providing scores to the land use layer. Starting from the Corine Land Cover 2012 layer, the biggest scores were given to the areas where humans carry out their activities (Table 1). For the areas where the categories 112 and 121 overlap, maximum scores (100, respectively 90) have been suggested, on the same scale used on the other layers, from 0 to 100 . The next category is 221 (vineyards), to which 70 score points were assigned, due to the preferential location of these areas, on steep slopes and degraded terrains, category that lies at the intersection between human presence and high vulnerability to landslides. At 
the opposite end of the scale, the farmland categories follow (non-irrigated arable land, complex cultivation patterns, land mainly occupied by agriculture, with significant areas of natural vegetation) alongside with pastures, to which 30 score points were assigned. These categories have indeed lower scores, because the arable terrain which is affected by natural degradation, can be anthropogenically adjusted with ease, through plowing techniques, thereby achieving a uniform land which gives it surface stability. Furthermore, the practice of monoculture does not have a negative effect on the landscape in depth, but rather in extent, through the increase of surface erosion, due to the direct exposure of soil to the pluviodenudational processes. Ultimately, the categories that have registered the lowest score on the land use layer, are represented by natural vegetation (both transition and forest vegetation). The transition vegetation, namely bushes, provides high protection to landslides, considering the type of roots that these plants possess (which penetrate the soil at higher depths, stabilizing it). The forest vegetation is very efficient in protecting the land both from surface and depth erosion, and also from the occurrence of potential landslides, because of the trees highly developed canopy (considering that the trees are broad-leaved), but also through the deep root network.

Table 1. - Landslide risk scores, associated with different land use categories (CLC 2012)

\begin{tabular}{c|l|c}
$\begin{array}{c}\text { CLC2012 } \\
\text { Code }\end{array}$ & \multicolumn{1}{|c}{ Class definition } & Risk score \\
\hline 112 & Discontinuous urban fabric & 100 \\
121 & Industrial or commercial units & 90 \\
211 & Non-irrigated arable land & 30 \\
221 & Vineyards & 70 \\
231 & Pastures & 30 \\
242 & Complex cultivation patterns & 30 \\
243 & Land principally occupied by agriculture, with significant areas of & 30 \\
311 & natural vegetation & 10 \\
324 & Broad-leaved forest & 20
\end{tabular}

The second factor used in the assessment of landslide risk is the lithologic parameter. The data has been processed using geological maps at a scale of 1:200 000 from 1968, (specifically the Focsani and Barlad sheets). The area of Tecucel river drainage basin sits exclusively on sedimentary rocks, which are divided into 4 classes: current river deposits; gravel, conglomerates, sands, clay and lignite; gravel with sands; and delluvial-proluvial deposits. Among the 4 classes, the biggest score was given to the clay class, of 100, because the clay substratum serves as a sliding surface. This characteristic is given by the property of clay particles to increase in volume, when they become saturated with water. The values suggested for the other classes are low, under 50, because they are characterized by rocks that have a high degree of permeability, or by the fact that they are located in the lower third of slopes, which does not confer a high risk degree to landslides(Table 2).

Table 2. - Landslide risk score, associated with different geological categories

\begin{tabular}{l|l} 
Class definition & Risk score \\
\hline Current river deposits & 10 \\
Gravel, conglomerates, sands, clays, lignite & 100 \\
Gravel, sands & 20 \\
Delluvial-proluvial deposits & 40
\end{tabular}


Soils can influence the occurence of a landslide through texture and degree of permeability. The data source regarding soil cover, consisted of soil maps (at a scale of 1: 200000), Focșani and Bârlad sheets. In Romania, the soil cover was divided into 19 texture classes, which range from sandy to clayey, from permeable soils to impermeable. All these classes have received scores according to their values, and from the resulted table, only the values that are applying to the Tecucel drainage basin were extracted (Table 3). In the study area, the soil cover is divided into 6 textural classes which vary from permeable strata (sandy - sandy-clayey) - that have received a low risk score, to the sandy-clayey class, that has the highest risk score, of 89 . The criterion by which the score is given, is the clay quantity that resides in the soil texture.

Table 3. - Landslide risk score, associated with different soil texture categories

\begin{tabular}{l|r} 
Class definition & Risk score \\
\hline Sandy-sandy-clayey & 11 \\
Sandy-clayey - clayey-sandy & 26 \\
Clayey-sandy -clayey & 47 \\
Varied texture & 58 \\
Clayey - clayey-sandy & 79 \\
Clayey-sandy & 89
\end{tabular}

Slope represents the inclination of the land surface from a horizontal plane. The importance of this parameter is proportional with the inclination, this characteristic directly influencing the magnitude, and the time needed for the geomorpholohical processes to develop (mainly gullies and landslides). Slope classification is made by using the inclination values, quantified in sexagesimal degrees or percents. In this case, the classification of this geomorphological parameter assumed some impediments, due to the necessity of a relevant range of classes for the study area, because of the predominance of low values, largely due to the location of the drainage basin. In Tecucel basin, the slope values are variable from $0^{\circ}$ to $44,46^{\circ}$ due to the relief configuration. The division of this interval into a range of classes represented a difficult phase in the process of slope classification, because of the number of classes and representative limit intervals needed. To overcome this matter, the slopes were classified in sexagesimal degrees after Kanji, which involved the use of 4 classes with slope values below $15^{\circ}$, between $15^{\circ}-30^{\circ}, 30^{\circ}$ $45^{\circ}$ and over $45^{\circ}$ [8]. To use this division, the method needed an adaptation, according to the values and reality on the field. Therefore, adding of an extra class with values between $0^{\circ}$ and $3^{\circ}$ was required as an extra step, to also represent the almost flat surfaces and those with low inclination, this class being relevant due to the location of the drainage basin. Also, lowering the limit from $45^{\circ}$ to $44^{\circ}$ was required, because the maximum slope values are not that high.

After adjusting the class values to the required needs, the slopes and their values from the study area could be emphasized, and cartographically represented, using the five, resulting classes.

Starting from the vector layers generated from the cartographic materials mentioned above, raster files were derived in GIS environment, for each layer. To obtain a consistent result of the four analyzed parameters, a conversion from vector to raster format was necessary. This was possible, by using the "Polygon to Raster" function (from ArcGis), the files being converted into rasters, and the pixels generated during this process meet two main conditions. Firstly, the pixel matrix from all layers, must overlap perfectly, in order to avoid the problems that might appear after the further addition, and secondly, the 
conversion must be made based on the attributes of the landslide risk scores, corresponding to the categories of each parameter. Such a evaluative approach to risk, based on many parameters, integrated into a final consistent layer, was used before, to evaluate other types of risks, by similar means [9].

The final phase implies the addition of the previously generated rasters, in Raster Calculator, the result following a 5 categories classification, to ease the interpretation of the problematic areas from the studied drainage basin.

\section{RESULTS AND DISCUSSION}

By analyzing the geomorphological risk from Tecucel drainage basin, a methodology which is based on factors with a major weight in the occurence of landslides, was applied. By analyzing the obtained result, the fact that the landslide risk is the highest in the middle sector of the basin, can be observed (Fig. 3), having a weight of $0,74 \%$ of its surface. This area is more exposed to this type of risk due to the specific characteristics of lithology and soil, such as: high proportion of clay, loamy-clay and loamy-loamy-clayey texture. In terms of land use, this area is located in the agricultural perimeter of the basin. The high risk to landslides class is also characterized by a median extent of the basin, but with a surface that adds up to 7,97\% of the basin (Table 4). In the same area, 5 settlements are concentrated, and through human activity, the risk can be intensified. In the same extent with the classified areas with very high and high risk, it can be observed that these appear on hill tops near Tecucel river and its tributary Valea Seacă.

At the other end of the risk scale, stands the northern part of the basin, which is covered in most of its area by deciduous forests and it is included in the Very Low and Low risk classes (with a cumulated weight of 51.49\%). The Low value of risk is also present as a small area strip, in the Southern area. Its occurance is caused by small slope values and the permeable lithologic subtratum (sands, gravel).

The class with the highest weight from the studied area is Medium risk, with a value of $39.3 \%$ and it overlaps the Southern-Central part of the basin. It is associated with the interfluvial area from the central part and in the South, although it's mostly agricultural, it is not affected by landslides over large areas.

Table 4. The weight classes of risk

\begin{tabular}{l|l} 
Risk classes & Percent \\
\hline Very low & 34.23 \\
Low & 17.26 \\
Medium & 39.3 \\
High & 7.97 \\
Very high & 0.74
\end{tabular}

The ravines were digitized from topographic maps, at the scale of 1:5000 and corrected, using aerial imagery and LiDAR data. Given the geographic context, the hypsometric scale of the basin and the main geomorphological processes occurring here, it is considered that the geomorphological risk is caused mainly by the possibility of landslide occurrence and by ravine existence and growth. The latter are present in high numbers all over the Barlad Plateau (inside which the study basin is located), and dominate the landscape by their high density in this area and by their large size. 


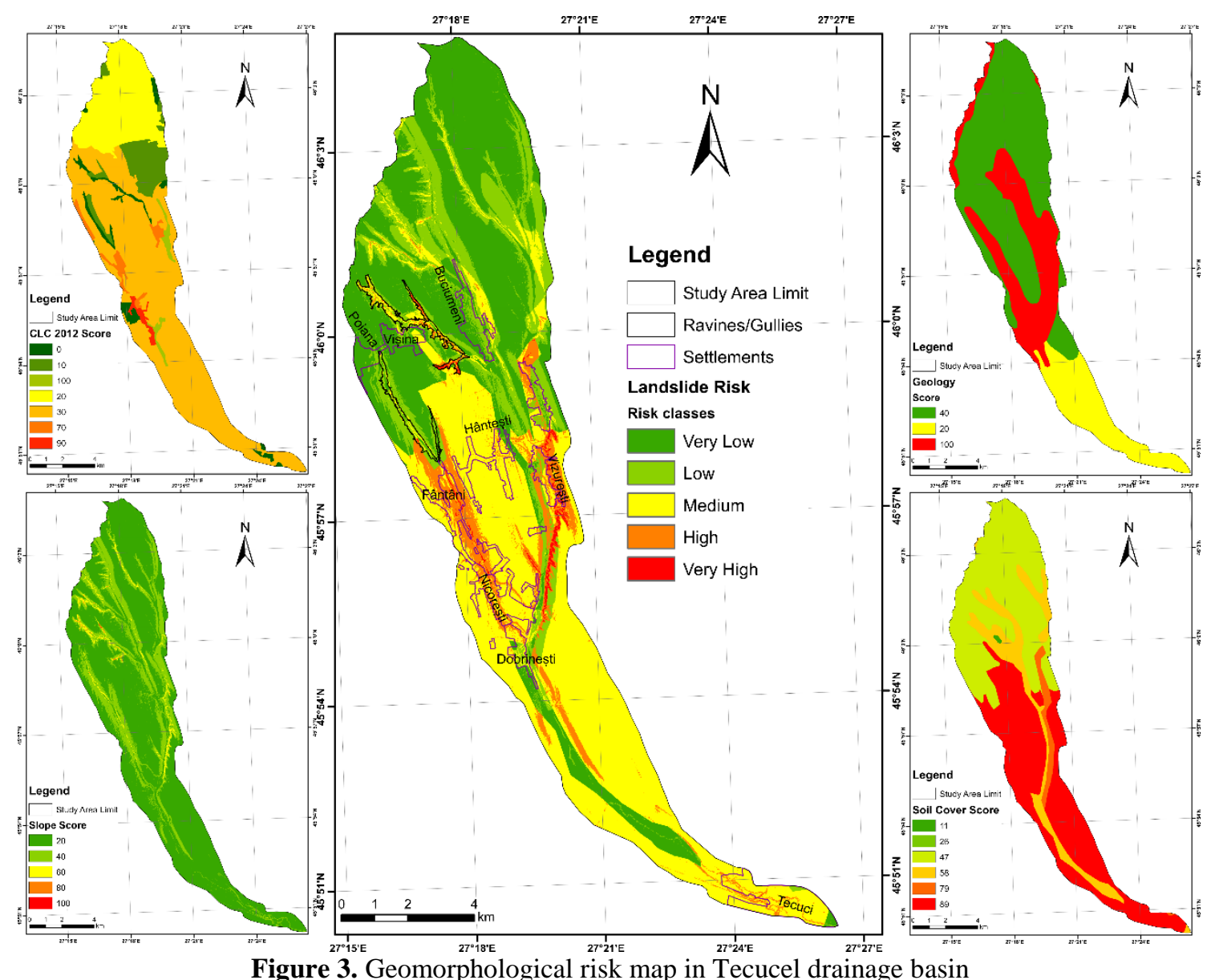

Figure 3. Geomorphological risk map in Tecucel drainage basin

Ravines predominate in the middle sector of Tecucel river and its tributaries, near some settlements. The risk is derived from the fact that some ravines are active and extending regressively, upstream and sideways, generating land instability. Fortunately, more than half of the affected area was forested, currently being stabilized.

\section{CONCLUSIONS}

Geomorphological risk assessment should be seen as a necessity in areas where landslides and gullying phenomena are omnipresent. For this reason, analyzes must be carried out, to better highlight these processes in order to help in decision-making in territorial planning, made by competent institutions.

The geomorphological risk analysis model, suggested in the present paper, is a multicriterial one, whose role was to integrate more spatial parameters (geology, land use, pedology and declivity), into a singular equation carried out in GIS environment, that would result in a consistent and easy to interpret layer. The result is even more precise, considering that to each parameter was given scores, for landslide risk, on a similar value scale with all the layers used (the values are distributed on a scale from 0 to 100).

In the case of the studied drainage basin, the geomorphological risk is located according to the main sections of the river. Therefore, the risk is reduced in the upstream sector, a medium risk is associated with the downstream sector, and in the central part, a mixture of risks is found; here, the land is prone to the highest geomorphological risk (both in terms of landslides and ravines). 
In conclusion, the proposed study model manages to achieve its purpose, emphasizing the most problematic land surfaces, prone to the analyzed risk, containing in a single thematic raster layer, the result of multiple factors, on which the discussed geomorphological processes are dependent.

\section{REFERENCES}

[1] Cardinali M., Reichenbach P., Guzzetti F., Antonini G., Galli M., Cacciano M., Castellani M., Salvati P., A geomorphological approach to the estimation of landslide hazards and risks in Umbria, Central Italy, Natural Hazards and Earth System Sciences, 2002, no. 2, pp. $57-72$

[2] Grozavu A., Mărgărint M.C., Patriche C.V., GIS applications for landslide susceptibility assessment: a case study in Iași County (Moldavian Plateau, Romania), Risk Analysis VII \& Brownfields V, 2010, WIT Press, pp. 393 - 404.

[3] Bălteanu D., Chendeș V., Sima M., Enciu P., A country-wide spatial assessment of landslide susceptibility in Romania, Geomorphology, Elsevier, 2010, 124, no 3-4, pp.102 $-112$.

[4] Zaharia L., Catană S., Crăciun E., Toroimac G.I., Flood vulnerability of Tecuci city: the role of natural and socio-economic factors, Riscuri și catastrofe, Romania, 2008, vol. 7 , no. 5 , pp. $130-140$.

[5] Necula M.F., Observation on the September 2007 flash flood in the Tecucel river basin, Present Environment and Sustainable Development, Romania, 2010, no. 4, 363 377.

[6] Romanescu G., Nicu I.C., Risk maps for gully erosion processes affecting archaeological sites in Moldavia, Romania, Zeitschrift für Geomorphologie, 2014, Volume 58, Number 4, pp. 509 - 523.

[7] Romanescu G., Le potentiel hydrique de surface dans les bassins versants des rivières Siret et Prut, Seminarul Geografic "Dimitrie Cantemir", 2007, no. 28, pp 13 - 31.

[8] Kanji M.A., Gramani M.F., Massad F., Cruz P.T., Araujo H.A., Main factor intervening in the risk assessment of debris flow, International Workshop on the Debris Flow Disaster of Dec 1999, Caracas, Venezuela, 2000.

[9] Sfî̀că L., Andrei A., Bărcăcianu F., Cojocaru S.., Enea A., Hapciuc O.E., Iosub M., Ichim P., Analysis of Snow - Drifting Vulnerability. Application to Botoşani County, Seminarul Geografic “Dimitrie Cantemir", 2013, no. 36, pp. 43 - 43. 